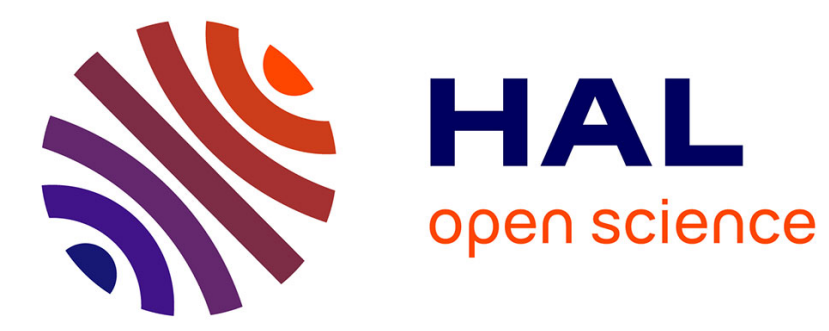

\title{
Normal, Abnormal, and Cascade Wittig Olefinations of $\alpha$-Oxoketenes
}

David Pierrot, Marc Presset, Jean Rodriguez, Damien Bonne, Yoann Coquerel

\section{To cite this version:}

David Pierrot, Marc Presset, Jean Rodriguez, Damien Bonne, Yoann Coquerel. Normal, Abnormal, and Cascade Wittig Olefinations of $\alpha$-Oxoketenes. Chemistry - A European Journal, 2018, 24 (43), pp.11110-11118. 10.1002/chem.201801533 . hal-01980647

\section{HAL Id: hal-01980647 https://hal.science/hal-01980647}

Submitted on 14 Jan 2019

HAL is a multi-disciplinary open access archive for the deposit and dissemination of scientific research documents, whether they are published or not. The documents may come from teaching and research institutions in France or abroad, or from public or private research centers.
L'archive ouverte pluridisciplinaire HAL, est destinée au dépôt et à la diffusion de documents scientifiques de niveau recherche, publiés ou non, émanant des établissements d'enseignement et de recherche français ou étrangers, des laboratoires publics ou privés. 


\title{
Normal, Abnormal, and Cascade Wittig Olefinations of $\alpha$-Oxoketenes
}

\author{
David Pierrot, ${ }^{[a]}$ Marc Presset, $^{[a, b]}$ Jean Rodriguez, ${ }^{[a]}$ Damien Bonne, ${ }^{*[a]}$ and Yoann Coquerel ${ }^{*[a]}$
}

\begin{abstract}
Oxoketenes generated in situ by a thermal Wolf rearrangement have been found to participate as 1,2- and 1,4-ambident C-electrophilic/O-nucleophilic reagents towards donor/acceptor carbonyl-stabilized Wittig ylides. This resulted in the very direct and practical syntheses of functionalized allenes by a normal Wittig olefination, $4 \mathrm{H}$-pyran-4ones by an abnormal Wittig olefination, or $4 \mathrm{H}$-pyranylidenes following a Wittig/abnormal Wittig cascade sequence as a
\end{abstract}

function of the substrates combination employed. Mechanistic experimental and computational studies provided a full rational for these reactivity switches. Some unusual mechanistic features for Lewis acid-free Wittig olefinations were identified in this series such as the involvement of betaine intermediates and some degree of reversibility in the normal Wittig olefination. The abnormal Wittig olefination was fully uncovered.

\section{Introduction}

$\alpha$-Oxoketenes are densely functionalized, highly reactive, electrophilic reaction intermediates of past and current great interest, not only because of mechanistic and theoretical considerations, but also because of their rich chemistry as building blocks in organic synthesis. ${ }^{[1]}$ With very few exceptions, they cannot be isolated under ordinary conditions and must be generated in situ. The two most convenient and commonly employed methods for the generation of $\alpha$-oxoketenes are the thermal decomposition of dioxinones, ${ }^{[2]}$ and the thermal or photochemical Wolff rearrangement of 2-diazo-1,3-dicarbonyl compounds. ${ }^{[3]}$ For the work described herein, and based on some precedents with simple ketenes, ${ }^{[4]}$ it was considered that unsymmetrically functionalized $\alpha, \alpha^{\prime}$-bisoxoallenes, for example, $\mathbf{4} \mathbf{a}-\mathbf{f}$, a class of chiral molecules difficult to obtain and only available through relatively complex multistep synthetic sequences, ${ }^{[5]}$ could be readily prepared by a Wolff rearrangement/Wittig olefination cascade reaction from diazo compounds and carbonyl-stabilized ylides via intermediate $\alpha$-oxo-

[a] Dr. D. Pierrot, Dr. M. Presset, Prof. Dr. J. Rodriguez, Dr. D. Bonne, Dr. Y. Coquerel

Aix Marseille Univ, CNRS, Centrale Marseille, iSm2

Marseille (France)

E-mail:damien.bonne@univ-amu.fr yoann.coquerel@univ-amu.fr

[b] Dr. M. Presset

Present address: Université Paris Est, ICMPE (UMR 7182), CNRS, UPEC 2-8 rue Henri Dunant, 94320 Thiais (France) ketenes. Several examples of the anticipated $\alpha, \alpha^{\prime}$-bisoxoallene synthesis could indeed be realized. However, in a number of cases the reaction between $\alpha$-oxoketenes and carbonyl-stabilized ylides followed alternative pathways involving either abnormal Wittig olefinations or cascade normal/abnormal Wittig processes to afford $4 \mathrm{H}$-pyran derivatives. In this article, we report in full detail the results of our experimental and theoretical investigations on the synthetically valuable chemical dichotomy in the reactions of $\alpha$-oxoketenes with carbonyl-stabilized Wittig ylides.

\section{Results and Discussion}

Our investigations started with the acyclic diazo compounds $\mathbf{1} \mathbf{a}-\mathbf{c}$, which were allowed to react with the representative Wittig ylides $2 \mathrm{a}-\mathrm{c}$ in toluene at 140 or $170^{\circ} \mathrm{C}$ under microwave irradiation conditions promoting rapid, quantitative, and regioselective (when applicable), Wolff rearrangements of the diazo compounds $\mathbf{1}$ into the corresponding $\alpha$-oxoketenes $\mathbf{3}$ (Scheme 1). ${ }^{[1 \mathrm{e}-\mathrm{h}]}$ As expected, the desired $\alpha, \alpha^{\prime}$-bisoxoallenes $4 \mathbf{a}-\mathbf{f}$ were obtained in fair to good yields, unlocking the practical synthesis of this valuable class of compounds. As an interesting observation, we also found evidence for the formation of a minor amount of $\gamma$-pyrone $5 \mathbf{I}(15 \%)$ in the reaction between diazo $1 \mathrm{a}$ and ylide $\mathbf{2} \mathrm{a}$. The formation of $\mathbf{5} \mathrm{I}$ can be rationalized by invoking a 1,4-C-electrophilic/O-nucleophilic behavior of the $\alpha$-oxoketene $\mathbf{3}$ a triggering an abnormal Wittig olefination (see mechanistic discussion below). ${ }^{[6]} \gamma$-Pyrones are valuable chemical moieties with a relatively frequent occurrence in biologically active natural and non-natural products. ${ }^{[7]}$ Existing synthetic methods forging $\gamma$-pyrones are often of limited breadth, hampering the exploration of their potential in chemistry and chemical biology, ${ }^{[7,8]}$ and alternative methods are desirable. 


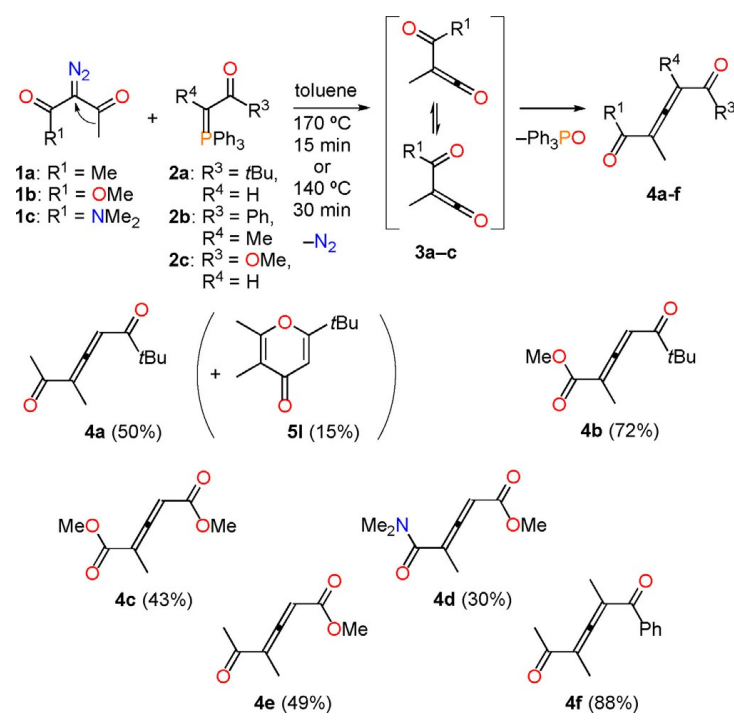

Scheme 1 . Synthesis of $\alpha, \alpha^{\prime}$-bisoxoallenes 4 by normal Wittig olefination of $\alpha$-oxoketenes 3 .

Stimulated and intrigued by these early results, a series of representative in situ generated $\alpha$-oxoketenes were allowed to react with a selection of carbonyl-stabilized Wittig ylides. It was actually found that $\alpha$-oxoketenes generally react with ketone-stabilized, and to some extent aldehyde-stabilized, ylides 2 via abnormal Wittig olefinations rather than regular Wittig olefinations, which resulted in the synthesis of polysubstituted and functionalized monocyclic and fused bicyclic $\gamma$-pyrones $\mathbf{5} \mathbf{a}-\mathbf{k}$ in fair to good yields (Scheme 2 ). The $\alpha$-oxoketene

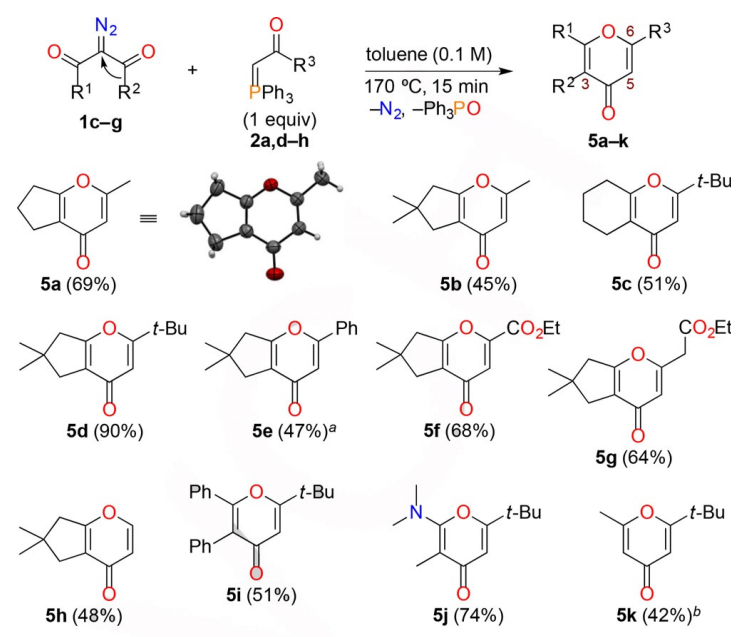

Scheme 2. Synthesis of $\gamma$-pyrones 5 by abnormal Wittig olefination of $\alpha$-oxoketenes 3. [a] The reaction also afforded the products $6 \mathrm{f}(22 \%)$ and iso- $6 \mathrm{f}$ (4\%), see text and Scheme 4. [b] Obtained from 2,2,6-trimethyl-4H-1,3dioxin-4-one ( $\mathbf{~ h}$ ) instead of 2-diazo-3-oxobutanal. intermediate derived from 2-diazo-1,3-cyclohexanone (1 d; $\mathrm{R}^{1}$, $\left.\mathrm{R}^{2}=-\left(\mathrm{CH}_{2}\right)_{3}-\right)$ reacted with the methyl ketone-stabilized Wittig ylide $2 \mathbf{d}\left(\mathrm{R}^{3}=\mathrm{Me}\right)$ to afford the fused bicyclic $4 H$-pyran-4-one $\mathbf{5} \mathbf{a}$ in $69 \%$ yield, the structure of which was confirmed by $\mathrm{X}$ ray diffraction analysis. Similarly, $4 H$-pyran-4-ones incorporating either an alkyl (in $\mathbf{5}$ b), hindered alkyl (in $\mathbf{5}$ c, $\mathbf{5}$ d and $\mathbf{5}$ i), phenyl (in $\mathbf{5 e}$ ), carbethoxyl (in $\mathbf{5} \mathbf{f}$ ), or carbethoxymethyl (in $\mathbf{5} \mathbf{g}$ ) substituent, or a simple hydrogen atom (in $\mathbf{5} \mathbf{h}$ ) at the 6 position, could be prepared. The reaction with the non-symmetric diazo ketoamide $1 \mathrm{c}\left(\mathrm{R}^{1}=\mathrm{NMe}_{2}, \mathrm{R}^{2}=\mathrm{Me}\right)$ afforded exclusively the 2dimethylamino-functionalized $4 \mathrm{H}$-pyran-4-one $\mathbf{5} \mathbf{j}$ in $74 \%$ yield, following a regioselective Wolff rearrangement of the diazo compound. A variation of the reaction was used for the preparation of the $\mathbf{4 H}$-pyran-4-one $\mathbf{5} \mathbf{k}$ having the 3 position unsubstituted $\left(R^{2}=H\right)$, which involved the thermolytic decomposition of 2,2,6-trimethyl-4H-1,3-dioxin-4-one ( $1 \mathrm{~h})$ for the generation of the required monosubstituted $\alpha$-oxoketene intermediate. ${ }^{[2]}$ In a control experiment, the irradiation with microwaves of a toluene solution of the diazo compound 1 e $\left(R^{1}, R^{2}=\right.$ $\left.-\mathrm{CH}_{2} \mathrm{C}\left(\mathrm{CH}_{3}\right)_{2} \mathrm{CH}_{2}-\right)$ and the phosphorous ylide $\mathbf{2} \mathbf{d}$ for 15 minutes at 80 or $130^{\circ} \mathrm{C}$ (which are temperatures that do not or only slowly promote the Wolff rearrangement of 1 e) left the starting materials essentially unchanged, showing that the ylide is inert toward the diazo compound at these temperatures. Overall, a simple and rapid synthetic method to prepare diversely substituted and functionalized $4 \mathrm{H}$-pyran-4-ones has been discovered, revealing that the abnormal Wittig olefination is not just a laboratory oddity ${ }^{[6]}$ but a general reaction. It nicely complements existing methods to synthesize $\gamma$-pyrones. ${ }^{[7,8]}$ Notably, ynol ethers have in the past been reported to undergo inverse-demand Diels-Alder cycloaddition with $\alpha$-oxoketenes to regioselectively afford $\gamma$-pyrones of type $\mathbf{5}$ having an alkoxide $\mathrm{R}^{3}$ substituent. ${ }^{[8, \mathrm{~d}]}$ As to the complementary method reported herein, the Wittig ylides $\mathbf{2} \mathbf{a}, \mathbf{d}-\mathbf{h}$ may be regarded as synthetic equivalents of terminal alkynes capable of undergoing regioselective [4+2] cycloaddition reactions with $\alpha$-oxoketenes (Scheme 3).

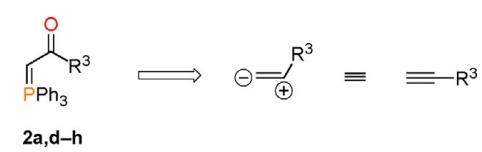

Scheme 3. Carbonyl-stabilized Wittig ylides as synthetic equivalents of alkynes.

In sharp contrast to the above results, the combination of the $\alpha$-oxoketene derived from the diazo $1 \mathrm{e}$ and the ester-stabilized Wittig ylide $2 \mathrm{c}$ did not produce the $\alpha, \alpha^{\prime}$-bisoxoallene $\mathbf{4 g}$ or the $\gamma$-pyrone $\mathbf{5 m}$, but the $4 H$-pyranylidene $\mathbf{6 a}$ in $43 \%$ yield together with a significant proportion of the $\alpha$-oxoketene dimer [Scheme 4, Eq. (a)]. Because two molecules of ylides were clearly incorporated in the product $6 \mathrm{a}$, the same reaction was attempted with two equivalents of the ylide, which afforded this time the $4 \mathrm{H}$-pyranylidene $6 \mathrm{a}$ in $89 \%$ yield. This pseudo three-component reaction could be generalized, allowing for the expeditious synthesis of $4 \mathrm{H}$-pyranylidenes $\mathbf{6} \mathbf{a}-\mathbf{f}$ [Scheme 4, 


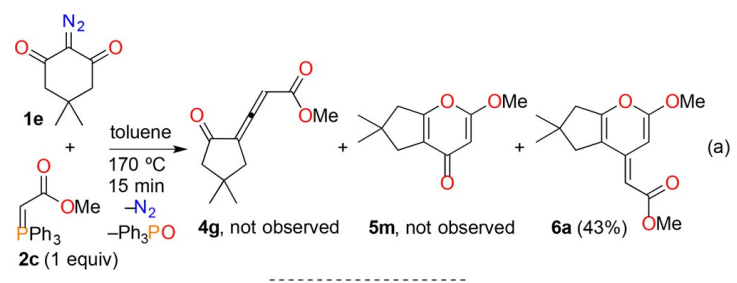

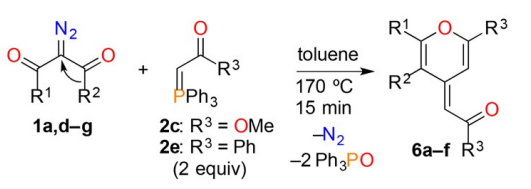

(b)
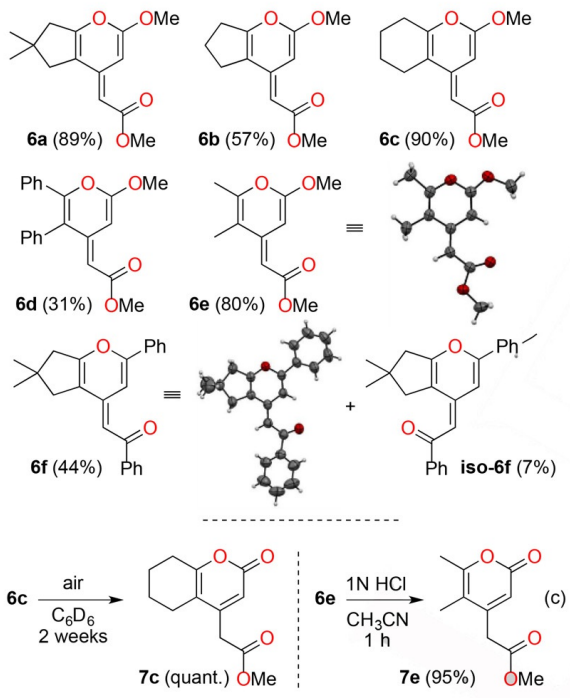

Scheme 4. Synthesis of $4 \mathrm{H}$-pyranylidenes 6 by a Wittig/abnormal Wittig cascade olefination of $\alpha$-oxoketenes.

Eq. (b)]. In the case of product $6 \mathrm{f}$, a minor amount of the diastereomer iso- $6 \mathrm{f}$ could also be isolated in $7 \%$ yield. The struc tures of $\mathbf{6 e}$ and $\mathbf{6} \mathrm{f}$ were secured by X-ray diffraction analyses. Notably, $4 H$-pyranylidenes of type 6 are donor-acceptors $\pi$ conjugated molecules with potential applications as nonlinear optical chromophores. ${ }^{[9]}$ The $4 \mathrm{H}$-pyranylidenes $6 \mathbf{a}-\mathbf{e}$, having a 2-methoxyl substituent, are relatively stable compounds showing no significant decomposition when stored neat in closed reaction vessels at $-18{ }^{\circ} \mathrm{C}$ for several months. However, $4 \mathrm{H}$-pyranylidene $6 \mathrm{c}$ could be cleanly converted into the corresponding $2 \mathrm{H}$-pyran-2-one $7 \mathrm{c}$ upon prolonged exposure to air at room temperature [Scheme 4, Eq. (c)]. Similarly, 4H-pyranylidene 6 e could be rapidly converted into $2 \mathrm{H}$-pyran-2-one $7 \mathrm{e}$ in the presence of aqueous $\mathrm{HCl}$ [Scheme 4, Eq. (c)]. These internal redox transformations are supposedly promoted by water. By extension, the synthetic approach to $4 \mathrm{H}$-pyranylidenes $6 \mathrm{a}$-e depicted in Scheme 4 also constitutes a practical method to prepare the corresponding substituted $2 \mathrm{H}$-pyran-2-ones, which is another important class of synthetically and biologically relevant molecules. ${ }^{[10]}$
To identify a plausible reaction pathway accounting for the formation of $4 \mathrm{H}$-pyranylidenes $\mathbf{6} \mathbf{a}-\mathbf{f}$, two control experiments were performed. First, a 1:1 mixture of $4 \mathrm{H}$-pyran-4-one $\mathbf{5 e}$ and Wittig ylide $2 \mathrm{e}$ in toluene was heated at $170^{\circ} \mathrm{C}$ for $15 \mathrm{~min}$ [Scheme 5, Eq. (a)]. Both starting materials were nearly quanti-<smiles>CC1(C)Cc2oc(-c3ccccc3)cc(=O)c2C1</smiles><smiles>O=C(C=Cc1ccccc1)c1ccccc1</smiles>

$\underset{170^{\circ} \mathrm{C}}{\stackrel{\text { toluene }}{\longrightarrow}}$ no reaction (a) $2 e$ (1 equiv)<smiles>COC(=O)C=C(C)C(C)=O</smiles><smiles>COC(=O)/C=C\c1ccccc1</smiles>

$\underset{170^{\circ} \mathrm{C}}{\stackrel{\text { toluene }}{\longrightarrow}}$<smiles>COC(=O)/C=C1\C=C(OC)OC(C)=C1C</smiles>

Scheme 5. Control experiments.

tatively recovered, and no formation of the $4 H$-pyranylidenes $\mathbf{6 f}$ or iso- $\mathbf{6} f$ could be evidenced, ruling out the possibility for a Wittig reaction between the ketone carbonyl group in $4 \mathrm{H}$ pyran-4-one $\mathbf{5 e}$ and phosphorous ylide 2 e. ${ }^{[11]}$ Second, a 1:1 mixture of allene $4 \mathrm{e}$ and Wittig ylide $2 \mathrm{c}$ in toluene was heated at $170^{\circ} \mathrm{C}$ for 15 minutes [Scheme 5, Eq. (b)]. Pleasingly, the analysis of the product reaction mixture evidenced the clean and efficient formation of $4 \mathrm{H}$-pyranylidene $6 \mathrm{e}$, pointing to allene $4 \mathrm{e}$ as a key intermediate capable of undergoing an abnormal Wittig olefination step in the cascade transformation $1 \mathrm{a}+2 \mathrm{c} \rightarrow \mathbf{6 e}$

Based on the above experimental data, it was enticing to postulate some empirical rules governing the fate of the reactions of carbonyl-stabilized phosphorous ylides with $\alpha$-oxoketenes: 1) $\alpha, \alpha^{\prime}$-bisoxoallenes of type 4 may be obtained by standard Wittig olefinations of acyclic-only $\alpha$-oxoketenes; 2) ketone-stabilized Wittig ylides generally react with $\alpha$-oxoketenes to give $\gamma$-pyrones of type $\mathbf{5}$ through abnormal Wittig olefinations; 3 ) ester-stabilized ylides react with $\alpha$-oxoketenes by a pseudo three-component Wittig/abnormal Wittig cascade olefination to afford $4 H$-pyranylidenes of type 6 via the corresponding $\alpha, \alpha^{\prime}$-bisoxoallene intermediates 4 ; and 4 ) the phenyl ketone-stabilized ylide $2 \mathrm{e}$ is a border case. However, the actual reasons dictating the divergent reactivities observed in these series warranted further research. With the intention to elucidate the mechanism of the abnormal Wittig olefination and to identify the origin of the dichotomy in the reactions of carbonyl-stabilized Wittig ylides 2 with $\alpha$-oxoketenes 3, we embarked on a detailed mechanistic computational study using DFT methods. This part of the study revealed several unusual features for Wittig olefinations. As a short background on the classical Wittig olefination, it is now generally accepted that the lithium salt-free Wittig olefination of a carbonyl compound with a carbonyl-stabilized phosphorous ylide is a three-step process initiated by an irreversible regio- and stereoselective $[2+2]$ cycloaddition between the $\mathrm{C}=\mathrm{O}$ bond of the carbonyl compound and the $\mathrm{C}=\mathrm{P}$ bond of the ylide, leading to an oxaphosphetane intermediate. ${ }^{[12]}$ Given that bond-forming and 
-breaking events at pentavalent bipyramidal phosphorus atoms preferentially occur from apical positions, the oxaphosphetane intermediate then requires a low-energy-demanding geometrical reorganization at the phosphorus atom, the socalled Berry pseudorotations, ${ }^{[13]}$ before its decomposition by a retro-[2+2] cycloaddition affording the olefin product and triphenylphosphine oxide. To get a realistic model for the Wittig olefinations described herein, calculations were performed at the B3LYP/6-311 + $+G(d, p) / / B 3 L Y P / 6-31+G(d)$ level of theory including a continuum description of solvation effects, and, importantly, with the full $\mathrm{PPh}_{3}$ ylides to account for all the steric and electronic effects. ${ }^{[14]}$ Both the normal and abnormal Wittig olefinations of the $\alpha$-oxoketene $\mathbf{3} \mathbf{d}$ having a blocked s-cis conformation were comparatively examined with the ketone-stabilized ylide $\mathbf{2} \mathbf{d}$ and the ester-stabilized ylide $\mathbf{2 c}$ (Figures 1-5). Importantly, all reactions were found to be initiated by the formation of a covalent bond between the nucleophilic ylidic carbon atom and the electrophilic ketene carbon atom to produce, respectively, the stabilized betaine intermediates I and $\mathbf{V}$ with a reasonable barrier (Figure 1). All efforts directed at the identification of alternative processes excluding the intermediary of the betaines I or $\mathbf{V}$ remained fruitless. Significantly, betaine intermediates were previously demonstrated not to form in the course of standard Lewis acid-free Wittig olefinations, ${ }^{[12]}$ and on that matter the reactions described herein are peculiar. The strain release resulting from the $\mathrm{sp}$ to $\mathrm{sp}^{2}$ rehybridization at the addition carbon atom together with the formation of $\pi$ extended zwitterionic ketoenolates leading to six-membered chelates by hydrogen bonding certainly contribute to the stabilization of betaines I and $\mathbf{V}$.

For the synthesis of the $\gamma$-pyrone $\mathbf{5}$ a (Figure 2), betaine I adopts the geometry $\mathrm{l}^{\text {bis }}$ suitable for the formation of the tricyclic oxaphosphetane intermediate II by a hemiacetalization/oxaphosphetane formation cascade. In oxaphosphetane II, the oxygen atom of the former acetyl stabilizing group of the ylide is in an apical position (with a $11.8^{\circ}$ deviation from alignment) at the phosphorus atom that adopts a trigonal bipyramid ge-
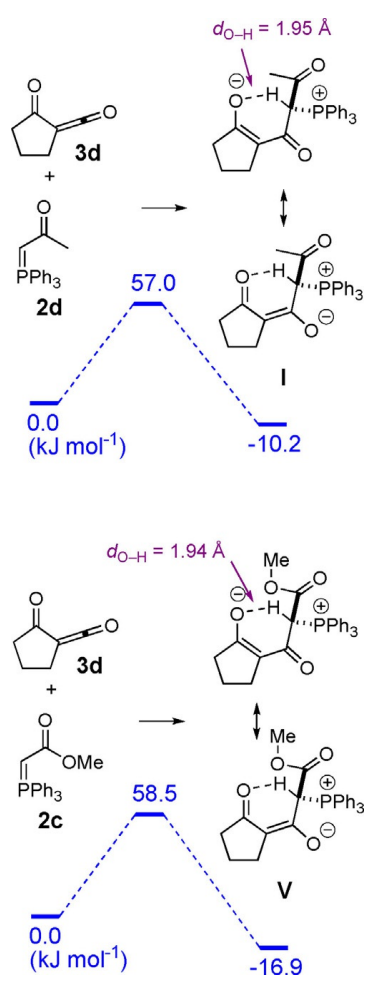

Figure 1. Reactions of $\alpha$-oxoketene $\mathbf{2}$ a with acetyl-stabilized Wittig ylide 3 a and methyl ester-stabilized ylide $3 \mathbf{h}$ to produce betaines $\mathbf{I}$ and $\mathbf{V}$, respectively. All energies are Gibbs free energies expressed in $\mathrm{kJ} \mathrm{mol}^{-1}$.

ometry. A geometrical reorganization at the pentavalent phosphorous atom (Berry pseudorotation) is then necessary to obtain the oxaphosphetane intermediate $\mathbf{I I}^{\text {bis }}$, having this time the former ylidic carbon atom in an apical position (with a $21.5^{\circ}$ deviation from alignment). This conformational change

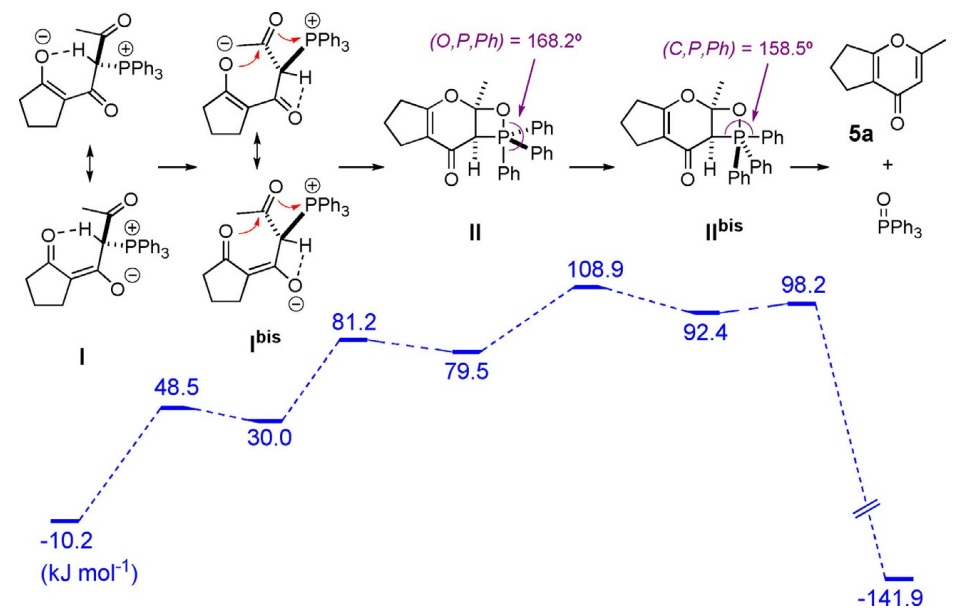

Figure 2. Energy profile of the reaction leading to $\gamma$-pyrone $\mathbf{5} \mathrm{a}$. All energies are Gibbs free energies expressed in $\mathrm{kJ} \mathrm{mol}^{-1}$. 


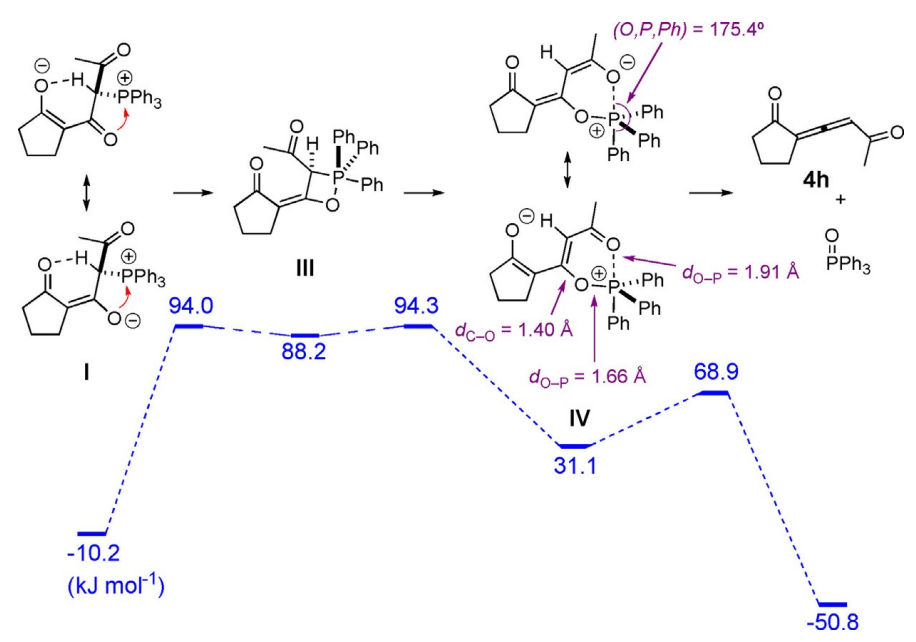

Figure 3. Energy profile of the reaction leading to allene $\mathbf{4 h}$ (not observed experimentally). All energies are Gibbs free energies expressed in $\mathrm{kJ}^{\mathrm{mol}}{ }^{-1}$.

was determined as the rate-limiting step of the overall transformation, with an activation energy of $+119.1 \mathrm{~kJ} \mathrm{~mol}^{-1}$ relative to the energy of the stabilized betaine intermediate $\mathbf{I}$. It is truly surprising that a simple Berry pseudorotation process is the actual rate-limiting step of the reaction leading to $\mathbf{5} \mathbf{a}$. Finally, decomposition of the oxaphosphetane II $^{\text {bis }}$ occurs with a low barrier $\left(5.8 \mathrm{~kJ} \mathrm{~mol}^{-1}\right)$ by a very asynchronous and exothermic retro- $[2+2]$ cycloaddition with the rupture of the $\mathrm{P}-\mathrm{C}$ bond largely in advance to the one of the $\mathrm{O}-\mathrm{C}$ bond, to give the $\gamma$-pyrone product $\mathbf{5} \mathbf{a}$ and triphenylphosphine oxide.

For the concurrent synthesis of the $\alpha, \alpha^{\prime}$-bisoxoallene $4 \mathbf{h}$ from the same substrates, which is not observed experimentally, it was found that the betaine intermediate I can cyclize to the oxaphosphetane intermediate III, having the former ylidic carbon atom in an apical position (Figure 3). The expected oxaphosphetane intermediate, having the oxygen atom of the former ketene carbonyl group in an apical position, is actually formed as a shoulder on the raising energy profile from $I$, and requires no significant activation energy (see the Supporting Information for details). Very surprisingly, and in sharp contrast to the well-established oxaphosphetane decomposition process by asynchronous retro-[2+2] cycloaddition (e.g. II ${ }^{\text {bis }} \rightarrow \mathbf{5}$ a in Figure 2), the only reaction path we could identify for the decomposition of III is a two-step process. Indeed, oxaphosphetane III was found to evolve by rupture of the C-P bond and some conformational change to afford the unusual betaine intermediate $\mathbf{I V} .^{[15]}$ Intermediate IV, which shows both a covalent $\mathrm{O}-\mathrm{P}$ bond $\left(d_{\mathrm{O}-\mathrm{P}}=1.66 \AA\right)$ and an electrostatic $\mathrm{O}^{-} / \mathrm{P}^{+}$ stabilizing interaction $\left(d_{\mathrm{O}-\mathrm{p}}=1.91 \AA\right)$, may be regarded as a Lewis pair adduct between triphenylphosphine oxide and the $\alpha, \alpha^{\prime}$-bisoxoallene $4 \mathrm{~h}$ (with $d_{\mathrm{c}-\mathrm{O}}=1.40 \AA$ ) stabilized by an electron retro-donation from the negatively charged oxygen atom of the acetyl group in the apical position (with a $4.6^{\circ}$ deviation from alignment) to the electron-demanding phosphorus atom. The separation of this Lewis pair can occur with a small barrier $\left(+37.8 \mathrm{~kJ} \mathrm{~mol}^{-1}\right)$ to afford the $\alpha, \alpha^{\prime}$-bisoxoallene $4 \mathrm{~h}$ and triphenylphosphine oxide.
Overall, these calculations indicate that the $\gamma$-pyrone abnormal Wittig product $\mathbf{5 a}$ is the thermodynamic product by $91.1 \mathrm{~kJ} \mathrm{~mol}^{-1}$, and that the allene regular Wittig product $4 \mathrm{~h}$ is the kinetic product by only $14.6 \mathrm{~kJ} \mathrm{~mol}^{-1}$. ${ }^{[16]}$ To experimentally demonstrate possible reversibility in the abnormal Wittig olefination leading to the $\gamma$-pyrone $5 \mathbf{I}$ (Scheme 1), a deuterated benzene solution of allene $4 \mathrm{a}$ was heated 30 minutes at $200^{\circ} \mathrm{C}$ in the presence of triphenylphosphine oxide with an internal standard (Scheme 6). The ${ }^{1} \mathrm{H}$ NMR analysis of the resulting mix-

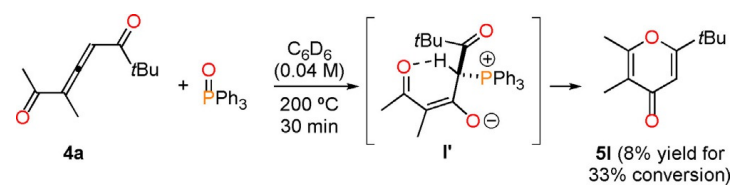

Scheme 6. Experimental proof for the possible retro-Wittig process leading to $5 \mathrm{I}$.

ture revealed the formation of $8 \%$ of the expected $\gamma$-pyrone $5 \mathrm{I}$ together with the presence of $67 \%$ unreacted $4 \mathrm{a}$ and some unidentified products. A similar reaction performed without triphenylphosphine oxide showed no significant reaction of $4 \mathrm{a}$. Although poorly efficient, the rearrangement of $4 \mathrm{a}$ into $5 \mathrm{I}$ in the presence of triphenylphosphine oxide, presumably involving the betaine $\mathrm{I}^{\prime}$, points out the existence of a kind of retroWittig process with a $\mathrm{C}=\mathrm{O}$ bond being created from a $\mathrm{C}=\mathrm{C}$ bond and triphenylphosphine oxide.

We next examined computationally the reactions of the model $\alpha$-oxoketene $\mathbf{3} \mathbf{d}$ with the ester-stabilized Wittig ylide $\mathbf{2 c}$. Paralleling the findings shown in Figure 2, betaine $\mathbf{V}$ was found to evolve to the $\gamma$-pyrone product $\mathbf{5 n}$ by a cascade double cyclization, affording consecutively the two oxaphosphetane intermediates $\mathbf{V I}$ and $\mathbf{V I}^{\text {bis, }}$, the decomposition of which by a retro-[2+2] cycloaddition gives the product (Figure 4). Overall, the energy profiles depicted in Figure 2 and 


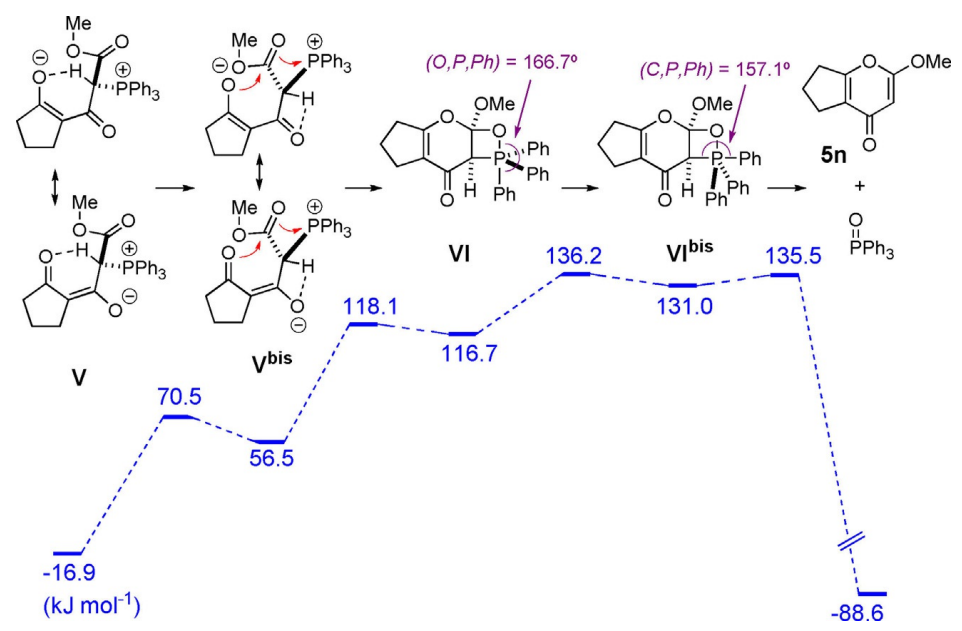

Figure 4. Energy profile of the reaction leading to $\gamma$-pyrone $5 \mathrm{n}$. All energies are Gibbs free energies expressed in $\mathrm{kJ} \mathrm{mol}^{-1}$.

Figure 4 are, as expected, very comparable; however, with a significant difference: the rate limiting step lies $+119.1 \mathrm{~kJ} \mathrm{~mol}^{-1}$ above the energy of betaine $\mathrm{I}$ in Figure 2 whereas it is now calculated at $+153.1 \mathrm{~kJ} \mathrm{~mol}^{-1}$ above the energy of betaine $\mathbf{V}$ in Figure 4 . In other words, in the ketonestabilized Wittig ylide series, the conversion of betaine I into $\gamma$ pyrone $5 \mathrm{a}$ can proceed at a rapid rate under the reaction conditions, whereas under similar conditions in the ester-stabilized Wittig ylide series the betaine $\mathbf{V}$ can only very slowly convert into $\gamma$-pyrone $\mathbf{5 n}$. This difference in reactivity actually reflects the lower reactivity of ester versus ketone carbonyl groups in anionic cascade processes. ${ }^{[17]}$

Finally, we examined the concurrent pathway leading to $\alpha, \alpha^{\prime}$-bisoxoallene $\mathbf{4} \mathbf{i}$ from betaine $\mathbf{V}$ (Figure 5 ). In this case, it was found that betaine $\mathbf{V}$ can readily undergo the $C \rightarrow O$ 1,3-

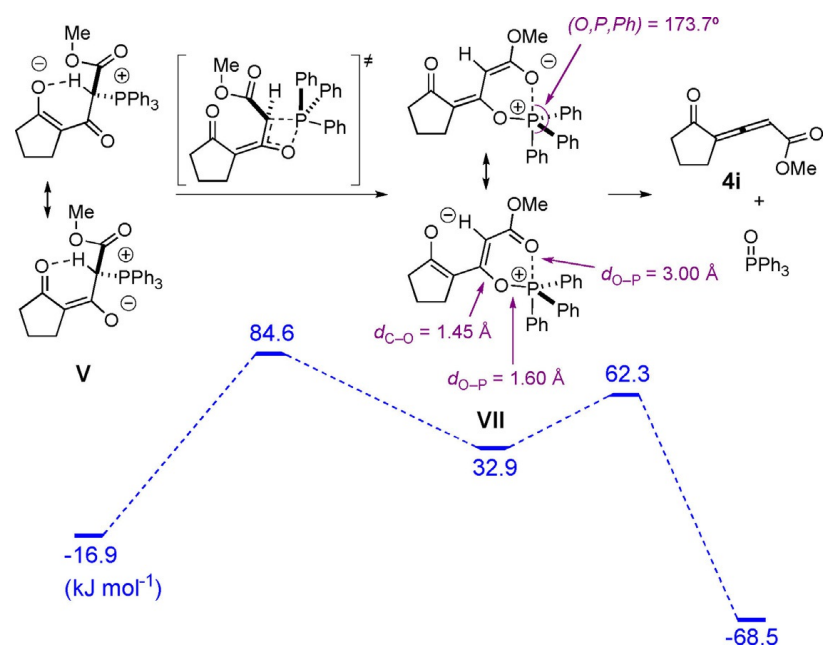

Figure 5. Energy profile of the reaction leading to allene $\mathbf{4} i$. All energies are Gibbs free energies expressed in $\mathrm{kJ} \mathrm{mol}^{-1}$. shift of the triphenylphosphonium group to give intermediate VII directly via a near planar oxaphosphetane transition state. The latter actually corresponds to the rupture of the C-P bond in an elusive oxaphosphetane intermediate having the former ylidic carbon atom in an apical position at phosphorous (i.e., the analogue of III with a methyl ester group in place of the acetyl group, see the Supporting Information for details). As before, intermediate VII may be regarded as a Lewis pair adduct between triphenylphosphine oxide and the $\alpha, \alpha^{\prime}$-bisoxoallene $4 \mathbf{i}$ stabilized by an electron retro-donation from the negatively charged oxygen atom of the carbonyl in the methyl ester group in the apical position (with a $6.3^{\circ}$ deviation from alignment) to the electron demanding phosphorous atom. However, this electrostatic $\mathrm{O}^{-} / \mathrm{P}^{+}$interaction is much weaker than above $\left(d_{\mathrm{O}-\mathrm{p}}=3.00 \AA\right)$, resulting in a less stabilized Lewis pair (compare the relative stabilities of IV and VII). This is easily rationalized by the preferred delocalization of the negative charge in VII on the distal ketone carbonyl oxygen atom rather than the methyl ester one. As above, the separation of the Lewis pair VII occurs with a small barrier (+ $29.4 \mathrm{~kJ} \mathrm{~mol}^{-1}$ ) to afford $\alpha, \alpha^{\prime}$-bisoxoallene product $4 \mathbf{i}$ together with triphenylphosphine oxide. The ratelimiting step of the overall transformation is the 1,3shift of the triphenyphosphonium group, with an activation energy of $+101.5 \mathrm{~kJ} \mathrm{~mol}^{-1}$ relative to the energy of the betaine $\mathbf{V}$. From this series of calculations, it was concluded that the preferential formation of $\alpha, \alpha^{\prime}$-bisoxoallene $4 \mathbf{i}$ over $\gamma$-pyrone $5 \mathbf{n}$ in the reaction between $\alpha$-oxoketene $2 \mathrm{a}$ and methyl esterstabilized Wittig ylide $\mathbf{3 h}$ is under sharp kinetic control, with the formation of the allene being ca. $10^{6}$ times faster than the formation of the pyrone.

The above model study shows that ester-stabilized Wittig ylides react with $\alpha$-oxoketenes to afford preferentially the corresponding $\alpha, \alpha^{\prime}$-bisoxoallenes $\mathbf{4}$ 
by a normal Wittig olefination. In practice, however, and with the exception of the reactions in the acyclic series presented in Scheme 1 , these reactions afforded the corresponding $4 \mathrm{H}$-pyranylidenes $\mathbf{6} \mathrm{a}-\mathrm{f}$ by a pseudo three-component reaction involving two equivalents of ylide (Scheme 4). Given that the $\alpha, \alpha^{\prime}-\mathrm{bi}$ soxoallene $4 \mathrm{e}$ has been shown to be an intermediate in the synthesis of $4 \mathrm{H}$-pyranylidene $6 \mathrm{e}$ [Scheme 5, Eq. (b)], we propose that $4 \mathrm{H}$-pyranylidenes $\mathbf{6} \mathbf{a}-\mathbf{f}$ are obtained by a normal Wittig olefination/regioselective abnormal Wittig olefination cascade. The $\alpha, \alpha^{\prime}$-bisoxoallene 4 initially obtained by normal Wittig olefination of $\alpha$-oxoketene 3 with ylide 2 would react with a second equivalent of ylide $\mathbf{2}$ to form betaine $\mathrm{A}$ (Scheme 7). This betaine would then undergo the regioselective hemiacetalization/oxaphosphetane formation cascade discussed herein for the abnormal Wittig olefination to afford the oxaphosphetane intermediate $\mathbf{B}$, the regioselectivity of the cyclization being dictated by the relative nucleophilicities of the distal oxygen atoms (ketone enolate vs. ester enolate). Finally, decomposition of B would give the $4 \mathrm{H}$-pyranylidene product 6 and triphenylphosphine oxide.

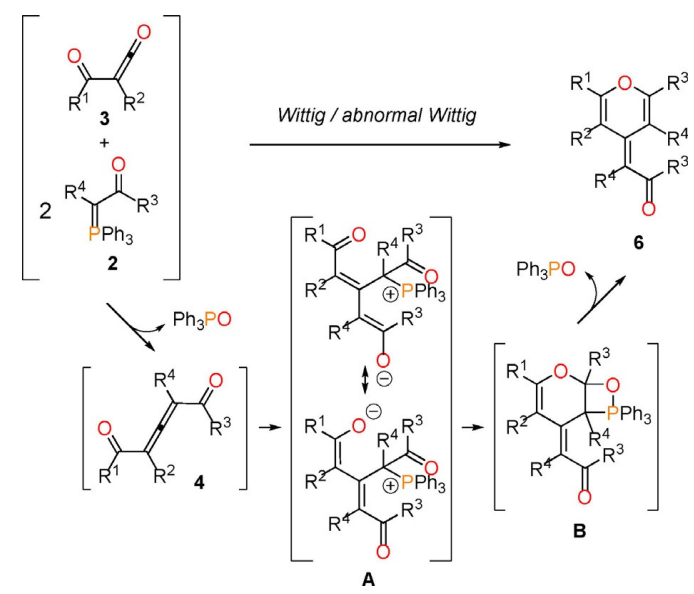

Scheme 7. Mechanistic hypothesis for the formation of $4 H$-pyranylidenes 6 via a Wittig/abnormal Wittig cascade reaction.

As shown in the example in Equation (a), Scheme 4, the $\alpha, \alpha^{\prime}$-bisoxoallene $\mathbf{4 g}$, having a blocked $s$-cis conformation of the $\alpha$-oxoallene moiety, reacts faster with the ester-stabilized ylide $2 \mathrm{c}$ than the $s$-cis $\alpha$-oxoketene derived from the diazo $1 \mathbf{e}$, precluding the isolation of $\alpha, \alpha^{\prime}$-bisoxoallene $\mathbf{4} \mathbf{g}$. However, this situation is reverted in the case of the $\alpha, \alpha^{\prime}$-bisoxoallenes $\mathbf{4 b}, \mathbf{c}, \mathbf{e}$, capable of adopting a s-trans conformation of the $\alpha$ oxoallene moieties (Scheme 1). As demonstrated by the model study, the abnormal Wittig olefination can only be operative with $\alpha, \beta$-unsaturated carbonyl compounds having an s-cis conformation. In the cases of $\alpha, \alpha^{\prime}$-bisoxoallenes $\mathbf{4} \mathbf{b}, \mathbf{c}, \mathbf{e}$, the favored s-trans conformations of their $\alpha$-oxoallene moieties are unproductive, slowing down their participation in abnormal Wittig processes and allowing their isolation under some conditions. Similarly, the $\alpha$-oxoketenes derived from the acyclic diazo compounds $1 \mathrm{a}, \mathrm{c}$ predominantly exist in their s-trans conformations, which here again slows down their abnormal Wittig reactivity to the benefit of the normal Wittig reactivity, allowing for the isolation of $\alpha, \alpha^{\prime}$-bisoxoallenes $4 \mathbf{a}, \mathbf{d}, \mathbf{f}$ (Scheme 1).

\section{Conclusions}

The reactions of $\alpha$-oxoketenes, prepared in situ by a thermal Wolff rearrangement of 2-diazo-1,3-dicarbonyl compounds, with carbonyl-stabilized Wittig ylides have been studied in detail. It was found that $\alpha$-oxoketenes generally react with ketone- and aldehyde-stabilized Wittig ylides as 1,4-ambident $\mathrm{C}$-electrophilic/O-nucleophilic reaction partners via an abnormal Wittig olefination, unlocking the synthesis of $4 \mathrm{H}$-pyran-4one ( $\gamma$-pyrone) derivatives with original substitution patterns. This reaction presumably involves some degree of thermodynamic control when compared to the normal Wittig olefination of the $\alpha$-oxoketenes, and some reversibility in the normal Wittig olefination was demonstrated: a premiere! In sharp contrast, ester-stabilized Wittig ylides were found to react with $\alpha$ oxoketenes through a normal Wittig olefination, affording $\alpha, \alpha^{\prime}$ bisoxoallenes. This reaction was shown to be under kinetic control when compared to the corresponding abnormal Wittig olefination. The actual reasons at the origin of the divergent reactivities observed for ketone-stabilized ylides on the one hand and ester-stabilized ylides on the other hand were investigated, notably through a comprehensive computational mechanistic study, and were ultimately found to reside in the higher electrophilicity of ketone carbonyl groups versus ester ones. In most cases, the $\alpha, \alpha^{\prime}$-bisoxoallene products were found to be reactive under the reaction conditions and capable, in turn, of undergoing an abnormal Wittig olefination with a second equivalent of Wittig ylide, leading to $4 \mathrm{H}$-pyranylidenes by a pseudo three-component reaction involving a Wolff/ Wittig/abnormal Wittig cascade sequence. Until now, the abnormal Wittig olefination was a laboratory oddity and the present work is the first report on its generalization, rationalization, and concrete synthetic applications. Overall, the chemical transformations described herein, involving the two venerable and thoroughly explored Wolff rearrangement and Wittig olefination, carry a significant improvement to the current knowhow for the selective synthesis of functionalized $4 \mathrm{H}$-pyran, and, to some extent, $2 \mathrm{H}$-pyran derivatives. In a broader meaning, the abnormal Wittig olefination of $\alpha, \beta$-unsaturated carbonyl compounds with carbonyl-stabilized Wittig ylides can now be added to the arsenal of synthetic methods to prepare $4 \mathrm{H}$ pyran derivatives. From a fundamental point of view, and contrary to the standard Lewis acid-free Wittig olefination of carbonyl compounds with carbonyl-stabilized phosphorous ylides, the Wittig and abnormal Wittig reactions described herein are likely to proceed via betaine intermediates.

\section{Experimental Section}

General procedure for the synthesis of $\alpha, \alpha^{\prime}$-bisoxoallenes $4 a-f$, $4 \mathrm{H}$-pyran-4-ones $5 \mathrm{a}-\mathrm{I}$, and $4 \mathrm{H}$-pyranylidenes $6 \mathrm{a}-\mathrm{f}$ : A $10 \mathrm{~mL}$ seal- 
able oven-dried tubular reaction vessel was charged with diazo compound 1 (ca. $0.2-1.0 \mathrm{mmol}$ ), phosphorous ylide 2 (1.0 or 2.0 equiv), and dry toluene $(2 \mathrm{~mL})$. The resulting heterogeneous mixture was subjected to microwave irradiation to reach $170^{\circ} \mathrm{C}$ as fast as possible and held at that temperature for 15 minutes, after which the reaction mixture was cooled to $55^{\circ} \mathrm{C}$ with an air flow. The resulting solution was concentrated under vacuum and directly purified by silica gel flash chromatography to afford the pure product.

CCDC $1550800(5 a), 1550801(6 e)$ and $1550802(6 \mathrm{f})$ contain the supplementary crystallographic data for this paper. These data can be obtained free of charge from The Cambridge Crystallographic Data Centre.

\section{Acknowledgements}

We thank Dr. Michel Giorgi (CNRS) for the X-ray structural analyses, Dr. Michel Rajzmann (Aix-Marseille Université) for assis tance in computational chemistry, and the Centre Régional de Compétences en Modélisation Moléculaire (Aix-Marseille Université) for computing facilities. Financial support from the Agence Nationale de la Recherche (ANR-13-JS07-0002-01), AixMarseille Université and the Centre National de la Recherche Scientifique (CNRS) is gratefully acknowledged.

\section{Conflict of interest}

The authors declare no conflict of interest.

Keywords: density functional calculations - microwave chemistry $\cdot$ reactive intermediates $\cdot$ synthetic methods $\cdot$ Wittig reactions

[1] Reviews: a) C. Wentrup, W. Heilmayer, G. Kollenz, Synthesis 1994, 1219 1248; b) G. Kollenz, S. Ebner in Science of Synthesis: Houben-Weyl Meth ods of Molecular Transformations, Vol. 23 (Ed.: R. Danheiser), Georg Thieme, Stuttgart, 2006, pp. 271 -349; c) K. P. Reber, S. D. Tilley, E. J. Sorensen, Chem. Soc. Rev. 2009, 38, 3022-3034; d) A. Ford, H. Miel, A. Ring, C. N. Slattery, A. R. Maguire, M. A. McKervey, Chem. Rev. 2015, 115, 9981 - 10080. For representative recent work: e) M. Presset, Y. Coquerel, J. Rodriguez, J. Org. Chem. 2009, 74, 415-418; f) M. Presset, Y. Coquerel, J. Rodriguez, Org. Lett. 2010, 12, 4212-4215; g) M. Presset, K. Mohanan, M. Hamann, Y. Coquerel, J. Rodriguez, Org. Lett. 2011, 13, 4124-4127 h) J. Galvez, J.-C. Castillo, J. Quiroga, M. Rajzmann, J. Rodriguez, Y. Coquerel, Org. Lett. 2014, 16, 4126-4129; i) P. Neupane, L. Xia, Y. R. Lee, Adv. Synth. Catal. 2014, 356, 2566-2574; j) Y. Dudognon, M. Presset, J. Rodriguez, Y. Coquerel, X. Bugaut, T. Constantieux, Chem. Commun. 2016, 52, 3010-3013.

[2] a) J. A. Hyatt, P. L. Feldman, R. J. Clemens, J. Org. Chem. 1984, 49, 5105 5108; b) R. Cookson, T. N. Barrett, A. G. M. Barrett, Acc. Chem. Res. 2015 48, 628-642

[3] Reviews: a) W. Kirmse, Eur. J. Org. Chem. 2002, 2193-2256; b) Y. Coquerel, J. Rodriguez in Molecular Rearrangements in Organic Synthesis (Ed.: C. Rojas), Wiley, Hoboken, 2015, Chap. 3, pp. 59-84.

[4] a) G. Wittig, A. Haag, Chem. Ber. 1963, 96, 1535-1543; b) H.-J. Bestmann, H. Hartung, Angew. Chem. 1963, 2, 214; c) H.-J. Bestmann, H. Hartung, Chem. Ber. 1966, 99, 1198-1207; d) G. Aksnes, P. Frøyen, Acto Chem. Scand. 1968, 22, 2347-2352; e) Z. Hamlet, W. D. Barker, Synthesis 1970, 543-544; f) R. A. Ruden, J. Org. Chem. 1974, 39, 3607-3608; g) R. Gompper, U. Wolf, Liebigs Ann. Chem. 1979, 1388-1405; h) R. W. Lang, H.-J. Hansen, Helv. Chim. Acta 1980, 63, 438-455; i) K. Diehl, G. Himbert, L. Henn, Chem. Ber. 1986, 119, 2430-2443; j) S. P. Marsden, P. C. Ducept
Beilstein J. Org. Chem. 2005, 1, 5; k) C.-Y. Li, X.-B. Wang, X.-L. Sun, Y. Tang, J.-C. Zheng, Z.-H. Xu, Y.-G. Zhou, L.-X. Dai, J. Am. Chem. Soc. 2007, $129,1494-1495$.

[5] For representative syntheses, see: a) T. Yoshino, F. Ng, S. J. Danishefsky, J. Am. Chem. Soc. 2006, 128, 14185-14191; b) T. Boisse, B. Rigo, R. Millet, J.-P. Hénichart, Tetrahedron 2007, 63, 10511-10520; c) M. A. Calter, N. Li, Org. Lett. 2011, 13, 3686-3689; d) I. Mizota, Y. Matsuda, S. Kamimura, H. Tanaka, M. Shimizu, Org. Lett. 2013, 15, 4206-4209.

[6] For the previous reports describing isolated examples of an "abnormal Wittig olefination", see: a) H. Strzelecka, M. Simalty-Siemiatycki, C. Prévost, C. R. Hebd. Séances Acad. Sci. 1963, 257, 926-928; b) M. von Strandtmann, M. P. Cohen, C. Puchalski, J. Shavel, Jr., J. Org. Chem. 1968, 33, 4306-4309; c) W. M. Abdou, N. A. F. Ganoub, Heteroat. Chem. 1992, 3, 133-137; d) W. M. Abdou, E.-S. M. A. Yakout, N. A. F. Ganoub, Tetrahedron 1995, 51, 11411-11420; e) F. Ramirez, O.P. Madan, C.P. Smith, J. Org. Chem 1965, 30, 2284-2290; f) F. Ramirez, O. P. Madan S. R. Heller, J. Am. Chem. Soc. 1965, 87, 731 -734; g) P. Crabbé, E. Díaz, J. Haro, G. Pérez, D. Salgado, E. Santos, Tetrahedron Lett. 1970, 50695072. In regards of the non-classical Wittig olefination, which corresponds to the olefination of carbonyl compounds other than ketones and aldehydes (e.g., esters, amides), we propose to name this transformation "the abnormal Wittig olefination" instead of "the internal Wittig reaction" as previously tentatively denominated.

[7] Reviews: a) A. K. Miller, D. Trauner, Synlett 2006, 2295-2316; b) W. Wilk, H. Waldmann, M. Kaiser, Bioorg. Med. Chem. 2009, 17, 2304-2309; c) P. Sharma, K. J. Powell, J. Burnley, A. S. Awaad, J. E. Moses, Synthesis 2011 2865-2892. For recent total syntheses: d) M. Henrot, A. Jean, P. A. Peixoto, J. Maddaluno, M. De Paolis, J. Org. Chem. 2016, 81, 5190-5201; e) L. Hoffmeister, T. Fukada, G. Pototschnig, A. Fürstner, Chem. Eur. J. 2015, 21, 4529-4533; f) J. C. Henrikson, T. K. Ellis, J. B. King, R. H. Cichewicz, J. Nat. Prod. 2011, 74, 1959-1964; g) V. Jeso, C. Yang, M. D. Cameron, J. L. Cleveland, G. C. Micalizio, ACS Chem. Biol. 2013, 8, 1241-1252.

[8] For approaches to di- or trisubstituted $\gamma$-pyrones involving inverse electron demand hetero Diels-Alder reactions with $\alpha$-oxoketenes, see: a) G. Jäger, J. Wenzelburger, Liebigs Ann. Chem. 1976, 1689-1712; b) E. Wenkert, T. P. Ananthanarayan, V. F. Ferreira, M. G. Hoffmann, H.-S. Kim, J. Org. Chem. 1990, 55, 4975-4976; c) G. Himbert, L. Henn, Liebigs Ann. Chem. 1987, 771-776; d) A. Stadler, K. Zangger, F. Belajb, G. Kollenz, Tetrahedron 2001, 57, 6757-6763. For an approach to $\alpha^{\prime}$-methoxy- $\gamma$-pyrones based on a desymmetrization strategy, see: e) H. Rosso, M. De Paolis, V. C. Collin, S. Dey, S. M. Hecht, C. Prandi, V. Richard, J. Maddaluno, J. Org. Chem. 2011, 76, 9429-9437. For approaches based on the cyclization of ynone derivatives, see: f) Y.-F. Qiu, F. Yang, Z.-H. Qiu, M.-J. Zhong, L.-J. Wang, Y.-Y. Ye, B. Song, Y.-M. Liang, J. Org. Chem. 2013, 78, 12018-12028; g) S. Dong, C. Fang, W. Tang, T. Lu, D. Du, Org. Lett. 2016, 18, 3882-3885. Selected miscellaneous approaches: h) D. L. Obydennov, G.-V. Röschenthaler, V. Sosnovskikh, Tetrahedron Lett. 2013, 54 , 6545-6548; i) D. Hobuß, S. Laschat, A. Baro, Synlett 2005, 123-124; j) J. Morris, G. P. Luke, D. G. Wishka, J. Org. Chem. 1996, 61, 3218-3220; k) C. A. B. Rodrigues, A. Misale, F. Schiel, N. Maulide, Org. Biomol. Chem. 2017, 15, 680-683; I) K. Onda, I. Hayakawa, A. Sakakura, Synlett 2017, $28,1596-1600$.

[9] A. B. Marco, P. M. Burrezo, L. Mosteo, S. Franco, J. Garín, J. Orduna, B. Diosdado, B. E. Villacampa, J. T. L. Navarrete, J. Casado, R. Andreu, RSC Adv. 2015, 5, 231-242, and references therein.

[10] Review: R. Pratapand, V. J. Ram, Tetrahedron 2017, 73, 2529-2590.

[11] For examples of Wittig-type olefinations of $4 \mathrm{H}$-pyran-4-one derivatives, see: a) K. Minami, T. Shirahata, M. Yohji, Chem. Lett. 2013, 42, 1548 1550; b) E. Azuma, K. Kuramochi, K. Tsubaki, Tetrahedron 2013, 69, $1694-1699$

[12] a) R. Robiette, J. Richardson, V. K. Aggarwal, J. N. Harvey, J. Am. Chem. Soc. 2006, 128, 2394-2409. Review on the Wittig olefination mechanism: b) P. A. Byrne, D. G. Gilheany, Chem. Soc. Rev. 2013, 42, 66706696.

[13] E. P. A. Couzijn, J. C. Slootweg, A. W. Ehlers, K. Lammertsma, J. Am. Chem. Soc. 2010, 132, 18127-18140.

[14] See Supporting Information for details. It may be noted that the present study is the first realistic computational mechanistic study on the Wittig reaction with ketenes. 
[15] Related dioxatriphenylphosphoranes have been isolated in the past, see for example: E. L. Clennan, P. C. Heah, J. Org. Chem. 1982, 47, 33293331.

[16] From this model study, the calculated half-life of $\mathbf{4 h}$ was estimated at $t_{1 / 2}=2.5 \mathrm{~h}$ (with the pre-exponential factor of the Eyring equation assumed to be 1), which appears over-estimated. Also, an overall barrier of $159.7 \mathrm{~kJ} \mathrm{~mol}^{-1}$ would be involved in the reaction $\mathbf{4} \mathbf{h} \rightarrow \mathbf{5} \mathbf{a}$, which also appears over-estimated. Given the large approximations of the model employed, relative errors of up to $\pm 40 \mathrm{~kJ} \mathrm{~mol}^{-1}$ are undoubtedly possible. For an excellent discussion on the accuracy of computational models in the case of polar reactions in solution such as the Wittig olefination, see: J. N. Harvey, Faraday Discuss. 2010, 145, 487-505.

[17] Selected reviews from our laboratory: a) X. Bugaut, D. Bonne, Y. Coquerel, J. Rodriguez, T. Constantieux, Curr. Org. Chem. 2013, 17, 1920-1928, b) D. Bonne, T. Constantieux, Y. Coquerel, J. Rodriguez, Org. Biomol. Chem. 2012, 10, 3969-3973; c) D. Bonne, T. Constantieux, Y. Coquerel, J. Rodriguez, Chem. Eur. J. 2013, 19, 2218-2231; d) D. Bonne, Y. Coquerel, T. Constantieux, J. Rodriguez, Tetrahedron: Asymmetry 2010, 21, 10851109; e) D. Bonne, T. Constantieux, Y. Coquerel, J. Rodriguez in Stereoselective Organocatalysis: Bond Formation Methodologies and Activation Modes (Ed.: R. R. Torres), Wiley, Hoboken, 2013, Chap. 16, pp. 559-585. 